Alma Mater Studiorum - Università di Bologna DEPARTMENT OF ECONOMICS

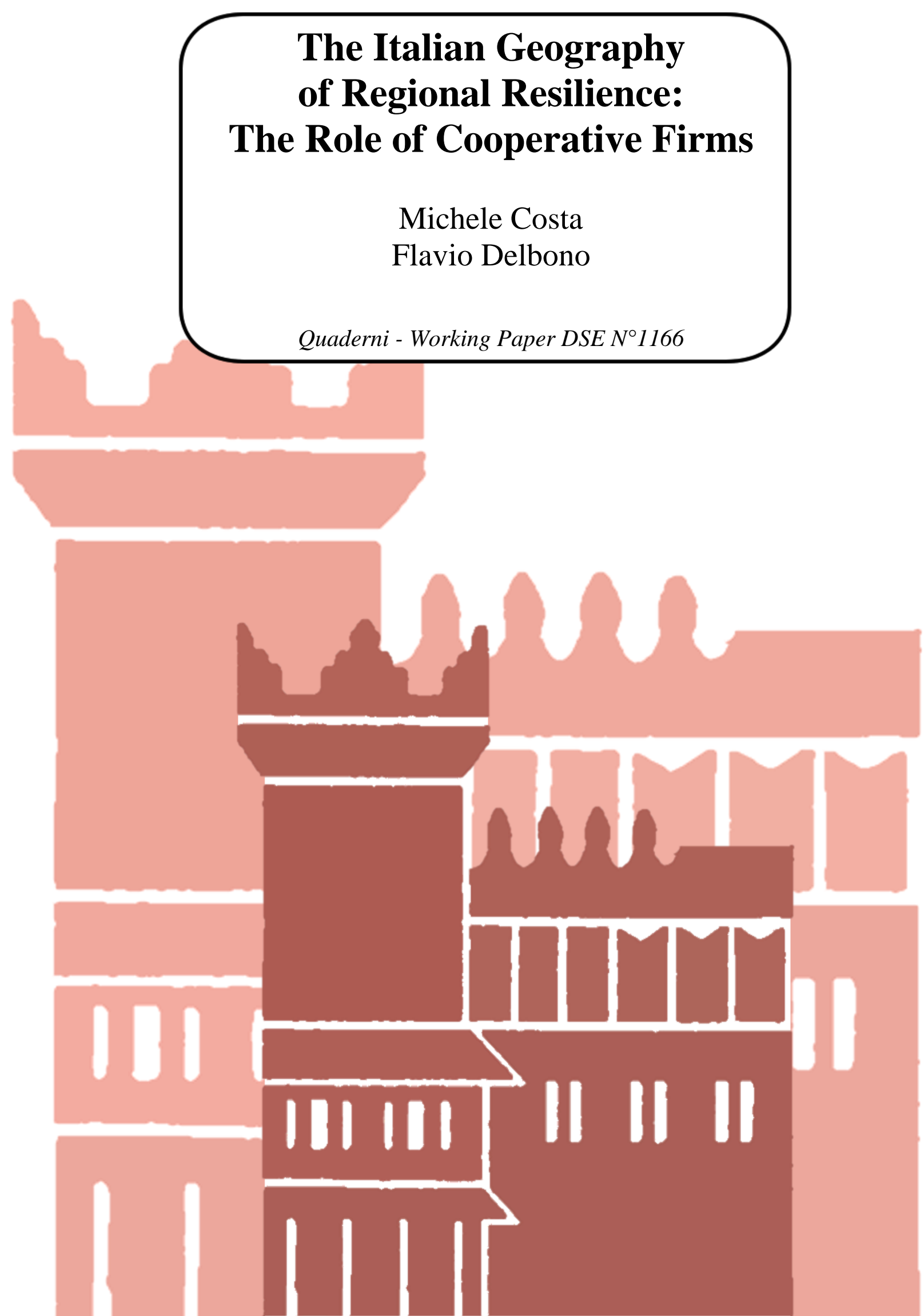




\title{
The Italian Geography of Regional Resilience: The Role of Cooperative Firms ${ }^{\S}$
}

\author{
Michele Costa $^{\circ}$ and Flavio Delbono* ${ }^{*}$
}

${ }^{\circ}$ Department of Economics, University of Bologna, P.za Scaravilli 2, 40126, Bologna, Italy

(michele.costa@unibo.it; flavio.delbono@unibo.it)

*Corresponding author

\begin{abstract}
We investigate the economic resilience of the Italian regions between 2008 and 2019. We then calculate some indices of resistance as well as recovery for both real GDP per capita and employment. We show that during (and after) recessions such indices follow different patterns and the Southern regions perform worse than the rest of the country. Then we try to detect if and how the composition of employment relates to regional resilience. We show that the size of the cooperative employment improves the overall resilience of regional employment, especially during recoveries. We also show and explain that this is not the case with cooperative added value as related to the resilience of regional GDP. Overall, the cooperative movement seems to positively contribute to the resilience of regional economies, supporting an inclusive growth especially through the employment channel.
\end{abstract}

JEL Codes: E32, J54, L21, R11

Keywords: macroeconomic shock, regional economies, employment, cooperative movement

$\S$ We are grateful to Daniele Brusha, Roberto Cellini, Guglielmo Barone, Luca Fanelli, Sergio Pastorello, Stefano Zamagni and Vera Zamagni for helpful comments and suggestions. The usual disclaimer applies. 
We study the economic resilience of the Italian regions between 2008 and 2019. Resilience is understood as ability to absorb macroeconomic shocks or to recover from them. We calculate indices of both types of resilience for all Italian regions between 2008 and 2019, a period in which the Italian economy experience two recessions. The resilience of a region is summarized by the percentage change in its employment or in its real GDP per capita, as compared to the corresponding national percentage change.

We show that: regions greatly differ in resistance; employment reacts more than GDP; Southern regions perform much worse than the rest of the country. We then try to explain differences in regional resilience and focus on the presence of cooperative firms. Such a presence is summarized by its employment and added value. We find that the employment of cooperative firms is positively and significantly associated to the resilience of overall regional employment. This is not the case for the cooperative added value when related to regional GDP per capita. Among the arguments apparently supporting these conclusions, we underline: (i) the comparatively high presence of cooperatives in labor-intensive and low added value (per employee) sectors, and (ii) their democratic governance which, consistently with the cooperative model, tends to protect employment especially during downturns. 


\section{Introduction}

Resilience has become an extremely fashionable term in recent years, well far away from the original meaning of the word ${ }^{1}$. For instance, the key instrument at the heart of the ongoing NextGenerationEU is the RRF (Recovery and Resilience Facility) and country-members have submitted their proposals to participate in the program. In the European Commission presentation of the RRF, one reads that "The aim is to mitigate the economic and social impact of the coronavirus pandemic and make European economies and societies more sustainable, resilient and better prepared for the challenges and opportunities". As for academic research, a growing number of empirical studies have addressed several facets of economic resilience (see Martin and Sunley, 2012), especially after the recession driven by the 2008 finacial crisis. Such a literature focuses on countries as well as sub-national territorial layers, given the vast heterogeneity within many national economies, e.g. the North-South dualism in Italy.

In this paper we investigate the resilience of the Italian regional economic systems (NUTS II) between 2008 and 2019. While shorter as compared to other studies, this time span uncovers the second major recession after WWII and precedes the major one (the pandemics-driven downturn of 2020) in peace times. In fact, the Italian economy experienced in 2009 a recessionary shock, begun in 2008, certified by a fall of about 5\% in real GDP. An almost double (about 9\%) decrease in real GDP happens in 2020. Hence, our preliminary goal amounts to using a fairly consolidated methodology (e.g., Martin 2012 and Fingleton et al. 2012) to update the results of previous studies about the resilience of Italian regions since we have at our disposal data on a recession (201114) and a recovery period (2015-19) that were unavailable in earlier researches.

\footnotetext{
${ }^{1}$ Clicking "resilience" on Google (September $3^{\text {rd }}, 2021,5.30 \mathrm{pm}$ ) one obtains 167,000,000 results. According to Modica and Reggiani (2015), the first known use of this term, in the field of physics, traces back to the Merriam-Webster Dictionary in 1824.
} 
However, the main purpose of our research deal with the attempt of explaining why economic resilience varies so much across regional systems in Italy in correspondence of (and/or after) the recessionary episodes observed in our time frame. Hence, we do not follow that part of the literature using resilience indices to detect their relationship with the growth rate of GDP or employment in the economic areas under exam. Instead, though aware that resilience is linked to very many social and economic factors, we focus on the regional differences in resilience and to this end we concentrate on the cooperative movement ${ }^{2}$, as summarized by the sizes of its added value and employment.

As established in the principles of the International Cooperative Alliance ${ }^{3}$, the mission of cooperative firms consists also in protecting their work force and the welfare of the communities they belong to. We provide additional evidence supporting that they tend to behave consistently with such a mission. Cooperative firms are marked by a democratic governance, in Italy they hire significant portions of labour force in some regions and are responsible for conspicuous shares of added value and employment nation-wide 4 , they do not discriminate workers and/or their members and they do not delocalize $^{5}$. Moreover, cooperatives distribute a small portion of net revenues to members and tend to stabilize employment while sacrificing profits during downturns.

\footnotetext{
${ }^{2}$ By cooperative movement we mean the set of cooperative firms and business groups controlled by cooperative firms: see Borzaga et al. (2019) for details about the cooperative groups in Italy. When referring to cooperative enterprises, we mean also cooperative groups or cooperative-controlled stock companies. On the importance of cooperative federations in various countries, see Dow (2018).

${ }^{3}$ https://weaversway.coop/pages/international-cooperative-principles.

${ }^{4}$ See, for instance, Zamagni and Zamagni (2011) for a thoughtful account of the Italian cooperative movement. To grasp an order of magnitude of the economic presence of cooperative companies worldwide, see ICA (2017); for the Italian economy, see Borzaga et al. (2019), Istat (2019) and Cori et al. (2021). According to Istat (2019), in 2015, including subsidiaries, the cooperative companies account for about $1,215,000$ employees $(7.4 \%$ of total employment in the Italian private sector) and over 32 billion euros (4.4\% of the corresponding added value)

${ }^{5}$ According to Borzaga et al. (2019), not only cooperative firms usually do not go off-shore, but they are rooted in very circumscribed areas: indeed, $99.6 \%$ of cooperative enterprises operate in a single region (84.7\% for business groups controlled by cooperatives).
} 
This countercyclical behaviour then protects employment and sustains labour incomes ${ }^{6}$.

We know that many countries exhibit notably large economic differences within their boundaries and such heterogeneity across territories is obviously concealed in crosscountry analyses ${ }^{7}$. Moreover, we may notice that the distribution of cooperative firms around the world is drastically different across and within countries (ICA 2017, Euricse 2020). Italy, which excels in the economic impact of the cooperative presence, is no exception. Hence, a region-based analysis of the impact of the Italian cooperative presence consistently follows.

As far as we know, this is the first attempt of measuring the relationship between economic resilience and the size of the cooperative movement at whatever administrative level. Our main findings can be summarized as follows.

- Employment reacts more heterogeneously than GDP per capita across regions, during and after all recessionary episodes.

- Both GDP per capita and employment of the Southern regions are less resilient (in resisting as well as in recovering) than the rest of the country.

- Controlling for the composition of employment and the geographic position, the cooperative employment is significantly and positively associated to the resilience of regional employment especially during recovery times.

\footnotetext{
${ }^{6}$ See, for instance, Menzani and Zamagni (2009), Perotin (2012), Delbono and Reggiani (2013), Euricse (2013), Zamagni (2015), Navarra (2016), Amorato (2017, ch. 3), Istat (2019), Caselli et al. (2021), Costa et al. (2021) and OECD (2021). The cooperative presence may be considered an indicator of the so-called "territorial capital", i.e., territorial-specific features to be assessed as local drivers of growth and resilience. On this, see Mazzola et al. (2018) and their analysis of the performance of Italian provinces (NUTS-3) during and after the 2008 financial crisis. Fratesi and Perucca (2018) carry out a similar analysis for a large group of European provinces.

${ }^{7}$ Differences among regions within the same country may be larger than differences between countries. In 2013, for example, the regional employment rate in Italy ranges from $40 \%$ in Campania to $73 \%$ in the autonomous province of Bolzano (a subset of the Trentino-Alto Adige region). This interval is about as large as the one observed across all OECD countries at that time (Veneri and Murtin, 2016).
} 
- The cooperative added value seems unrelated to the resilience of regional GDP per capita during recessions as well as recoveries.

The rest of the paper is organized as follows. In the next section we frame our work in the currently prevailing conceptual set-up and discuss the mostly related literature. In section 3 we illustrate our statistical tool-kit and we measure the resilience of the Italian regions. Section 4 presents an analysis of the regional differences in some resilience indices. Section 5 comments the relationship between resilience and the cooperative presnece. Section 6 concludes.

\section{The conceptual frame and the related literature}

The current use of the term resilience in economic debates - among scholars as well as among policy-makers - is much more recent with respect to its appearance in discussions nourished by other disciplines. The marked plurality in the very interpretation of what resilience may mean in the economic field has been masterfully scrutinized and fixed by Martin and Surley $(2015)^{8}$. We agree with their approach. More precisely, we adopt a combination of what they label as the ecological definition plus the engineering one (see their taxonomy in Table 1, p. 4). According to the former, resilience is understood as "ability to absorb", while the latter stands for "bounce back" from shocks. In widespread terms, we may refer to such attributes as resistance and recovery, respectively.

We borrow from their Table 3 some major issues and try to answer the derived questions dealing with the nature (and the time) of the shocks, the toughness of "victims" (firms, institutions, regions, ...) and their ability to recover. Last but not least,

\footnotetext{
${ }^{8}$ In a seminal paper, Martin (2012) had already proposed an approach to measure some keycomponents of what constitutes economic resilience of a territorial system. Sensier et al. (2016) expand such an approach and apply it to measure the resilience of regions in 28 European countries between 1990 and 2011.
} 
we shall address - and isolate an unavoidably partial answer to - the key question (Martin and Surley, 2015, p. 25): why do regions differ in resilience?

To go on quantitatively, one then needs resilience indices obtained by selecting the relevant variables to be tested. In the wake pioneered by Martin (2012) and proven also in Fingleton et al. (2012) and Martin et al. (2016), inter alia, we shall concentrate on relative measures of both employment and GDP per capita to detect the resilience of Italian regional economies during downturns and in recovery periods. Notice that here "relative" has a twofold acceptation: it means "percentage", but also "as compared to a benchmark" which, also in our analysis, will mainly be the national performance of the chosen variable (say, $\mathrm{X}$ ). Hence, the resulting index may be interpreted as a Regional Elasticity of $X$ :

$$
R E_{i t}=\left(\% X_{i t} / \% X_{N t}\right)
$$

if referred to region $i, N$ standing for National. $R E_{\text {it }}$ relates percentage variations in $X$ occurred in period $t$ in two different geographic entities (incidentally, the smaller one being a subset of the other one). We shall check the consequences of eliminating region $i$ from the denominator by computing the regional elasticity of region $i$ wrt the rest of the country (i.e., $\% X_{i t} / \% X_{N-i, t}$ ), in short $\mathrm{RE}_{\text {-it }}$.

As we said, in our study as in others that we will mention later in this section, the main chosen variables will be employment and GDP per capita, but the novelty of our approach lies in the attempt of explaining why these variables respond to shocks so differently across Italian regions vis-à-vis the national patterns. We actually acknowledge that "regional economic resilience is produced by a complex interplay of compositional, collective and contextual processes.... its mix of industries and firms by age, size, type, ownership and so on...." and that “... these factors are also closely interrelated with collective factors including the relationships and connectivity among and between firms and local and regional labour markets ..." (Martin and Surley 2015, p. 25, first italics added). Consistently, we focus on the impact of particular 
entrepreneurial entities, the cooperative ones, whose members, often workingmembers, own the company and act collectively through the cooperative movement in an articulated and multilayer interplay with local labour markets, institutions and the economic environment altogether.

The group of papers mostly related to our contribution includes a recent and rapidly growing academic literature dealing with regional resilience across European regions, especially in UK and Italy. Martin (2012) and Fingleton et al. (2012) are the first to introduce sensitivity indexes (the ones that we reinterpret as regional elasticities above) to measure regional resilience in terms of employment across UK regions between 1979 and 2010. Employment is chosen as a key variable because it is claimed that usually it takes longer to recoup than output. Martin (2012) focusses on three dimensions of resilience (resistance, recovery and renewal), neglecting the fourth (re-orientation) spelled out in his scheme (Martin 2012, p. 12). Controlling for sectorial composition, he then classifies regions according to how resistance and recovery combine during and after the three main recessions hitting the UK economy. The same geographic and temporal setting is investigated also in Fingleton et al. (2012) considering 4 recessionary shocks (with respect to Martin 2012, they consider also the OPEC-driven slum in the early ' 70 s of the past century). They show that the reaction to shocks (resistance) is a good predictor of the size of recovery. Moreover, they employ a Seemingly Unrelated Regression (SUR) model to estimate the impact of 4 recessions and 3 post-recession trends on employment growth rates across UK regions. This time span, including the dating of recessions, and the UK spatial framework considered in Fingleton et al. (2012) are used also by Martin et al. (2016) to evaluate the role of the economic structure (as proxied by the industry mix or the migration flows, for instance) in relationship to employment resilience.

Euroland and especially its eurozone subset are the geographic spaces considered by Fingleton et al. (2015) between 1980 and 2011. Testing resilience across regions by means of a spatial panel model with random effects, they show that the biggest impact 
of the financial crisis is experienced by isolated (Southern) territories, coinciding with those regions belonging to (low productivity) countries hit also by the sovereign debt crisis. Doran and Fingleton (2016) test individuals' resilience through the European Social Survey, collected between 2001 and 2008, to generate counterfactual for 2010. They aim at contrasting actual and counterfactual employment outcomes and confirm the conclusion of Fingleton et al. (2015) about the geographic distribution of resilience across European regions and typify the most resilient individuals. Cainelli et al. (2019). use a variant of Martin's (2012) measure of ecological resilience to investigate the ability to absorb the 2008-9 recession of a large group of Local Labor Systems (LLS) belonging to several European regions. They emphasize the role of industrial relatedness captured by an index of related variety.

Another set of papers concentrates on regional resilience in Italy, most of them employing the methodology pioneered by Martin (2012) and Fingleton et al. (2012). Cellini and Torrisi (2014) select 6 major shocks hitting the Italian economy in the very long-time frame 1890-2008/9, but they use GDP per capita instead of employment as key variable to measure the regional resilience and eventually perform a SUR estimation along the lines of Fingleton et al. (2012) ${ }^{9}$. One major finding is that shocks have permanent effects which differ across areas, "but there is limited heterogeneity in the ways in which different regions react and recover from common 'major' recessionary shocks" (p. 1791). Lagravinese (2015) considers three downturns occurred between 1970 and 2011 in Italy. He follows too the division of economic resilience in the pair resistance/recovery as measured by regional employment reactions. He shows that the composition of employment matters: regions accommodating comparatively large numbers of employees in service industries and public sector resist better than those regional economic systems featured by large shares of manufacturing and temporary workers. The importance of the resilience of

\footnotetext{
${ }^{9}$ Such an estimation consists in regressing the regional rate of growth of GDP per capita (or employment, as in Fingleton et al. 2012 and Di Caro 2015, for instance) by means of two groups of dummies corresponding to recessionary periods and recovery ones. Regional specificities are caught by differences within and between the two groups of coefficients associated to such dummies.
} 
the manufacturing sector on employment is underlined by Di Caro (2015) in the analysis of three recessions between 1977 and 2013 (see also Di Caro 2018). The dating of Italian recessions is at odds with other papers, as here the downturn attached to 1977 is related to two oil crises actually occurred in 1973 and in 1979, and also the financial crisis is treated as a unique recession from 2009 to 2013, although 2010 and 2011 are not considered as such from official Istat databases, for instance. A similar problem of dating problem arises with Martini (2020) who looks at resilience across Italian regions between 2000 and 2010. Her choice of resistance/recovery periods makes her conclusions hardly comparable with other related studies. Cellini et al. (2017) consider 4 recessions in the Italian economy between 1975 and 2011. Interestingly, they compare the contrasting outcomes resulting from choosing employment or output when testing the regional resilience. They also notice that the slum observed in 20089 is the only one in their time span in which both variables fall in all Italian regions. Faggian et al. (2017) divide the Italian territory into $686 L L S$ and measure the resistance to (and recovery from) the financial crisis of 2008-9. The reactions drastically vary across territories; a multinomial logit model identifies relevant factors other than the North-South dualism, like the industrial vocation and the population size. Iacobucci and Perugini (2021) consider the Italian provinces (Nuts 3) between 2004 and 2016. They show that both resistance and recovery indices à la Martin are significantly associated to a rich set of dimensions of the so-called Entrepreneurial Ecosystem.

\section{Regional resilience in Italy: data and statistics}

A preliminary issue deals with the temporary scan of shocks; as we noticed, different criteria lead to different, hardly comparable, conclusions. Recessions are usually identified through falls in GDP. However, when investigating the resilience of employment, one may notice that GDP per capita and employment are not synchronized at the national level. Hence, we prefer to follow a route different from the prevailing one in the literature. 
As for GDP, we select a variant of the strategy followed by Fingleton et al. (2012). The years of recessions are those featuring a negative rate of growth in the country's real GDP per capita ${ }^{10}$ and we too consolidate in a single shock the recessions occurring in consecutive years. As for the identification of the recovery period, this consists in the overall time interval between the end of a recession until another shock kicks-off ${ }^{11}$. Given the above identification of recessionary shocks, in our time span we detect in Italy 2 recessions (2008-9, 2012-14) and two post-recession periods (2010-11, 201519).

As for employment, we will refer to descent and ascent, depending on whether the national employment falls or rises, respectively. We will neglect a mild isolated change preceded and followed by changes of the opposite sign. Doing so, we will ignore the tiny increase occurred in 2011 ( $+0.27 \%$, corresponding to less than 67,000 employees) and identify a 6-years long descent (2008-13) and an equally long ascent (2014-19).

The dataset to be used in this section is entirely retrieved from Istat regional accounts. We shall employ yearly data because of the need to harmonize this dataset with the one that we will use in the next section. Indeed, while quarterly figures are delivered by Istat for regional employment, this is not the case for the corresponding figures (stemming from other datasets) if restricted to cooperative firms.

As for the notation, we indicate with $e_{i t}\left(E_{i t}\right)$ the regional elasticity of the employment of region $i$ at time $t$ (with respect to the national one) during descent (ascent). Similarly, we may denote by $a_{i t}\left(A_{i t}\right)$ the regional elasticity of the real GDP per capita of region $i$ at time $t$ (with respect to the national one), during recessions (recoveries).

\footnotetext{
${ }^{10} \mathrm{We}$ deflate nominal income through the Istat consumption price index. Fingleton et al. (2012) utilize GDP to identify recessions. Our choice is not immaterial to the identification of recessionary shocks: using GDP per capita (as Cellini and Torrisi 2014 do) makes 2014 the last year of the recession started in 2012, whereas using GDP leads to consider such a recession ended in 2013.

11 This choice would be questionable in very long-run time series, as pointed out by Cellini et al. (2017), because it might entail recovery phases lasting decades. This issue cannot arise within our fairly short time frame.
} 
The next two Tables present descriptive statistics for regional GDP per capita (Table 1) and employment (Table 2): $S D$ stands for standard deviation. At the national level, employment and GDP per capita, visualized in Figure 1A $(A$ mnemonics for Appendix), exhibit a positive correlation of 0.66 .

Table 1. Regional GDP per capita, descriptive statistics, yearly data, 2008-19

\begin{tabular}{lrrrr}
\hline & \multicolumn{2}{c}{ Levels } & \multicolumn{2}{c}{ Variations } \\
& Mean & SD & Mean & SD \\
\hline Italy & 28.317 & 839 & $-0,53$ & 2,26 \\
\hline Piedmont & 29.917 & 1.044 & $-0,56$ & 3,39 \\
Valle d'Aosta & 38.217 & 1.536 & $-0,65$ & 2,91 \\
Liguria & 30.866 & 1.008 & $-0,58$ & 2,37 \\
Lombardy & 37.653 & 1.163 & $-0,26$ & 2,79 \\
Trentino-Alto Adige & 40.772 & 772 & 0,16 & 1,57 \\
Veneto & 31.634 & 873 & $-0,38$ & 2,54 \\
Friuli-Venezia Giulia & 30.218 & 879 & $-0,54$ & 3,07 \\
Emilia-Romagna & 34.403 & 1.040 & $-0,36$ & 2,80 \\
Tuscany & 30.178 & 689 & $-0,38$ & 1,85 \\
Umbria & 25.582 & 1.400 & $-1,18$ & 3,09 \\
Marche & 26.676 & 784 & $-0,76$ & 2,32 \\
Lazio & 34.143 & 2.011 & $-1,39$ & 2,44 \\
Abruzzo & 24.575 & 546 & $-0,45$ & 2,31 \\
Molise & 21.045 & 1.397 & $-1,39$ & 2,92 \\
Campania & 18.355 & 713 & $-0,93$ & 1,86 \\
Apulia & 18.142 & 393 & $-0,39$ & 2,08 \\
Basilicata & 21.277 & 822 & $-0,01$ & 3,75 \\
Calabria & 17.087 & 736 & $-0,94$ & 1,73 \\
Sicily & 17.782 & 832 & $-1,12$ & 1,78 \\
Sardinia & 20.706 & 631 & $-0,46$ & 2,11 \\
\hline & & & & \\
\hline & & & \\
& & & & \\
& & & &
\end{tabular}

Notice that, at the national level, in our overall time frame, while employment mildly goes up $(0,17 \%$, Table 2$)$, GDP per capita falls (- $0.53 \%$, Table 1$)$ in all regions, except Trentino-Alto Adige. Hence, employment recoups faster than GDP per capita, most 
significantly in a group of regions of the Centre-North of the country ${ }^{12}$, with Lazio leading this group (Table 2).

Table 2. Regional employment, descriptive statistics (thousand), yearly data, 2008-19

\begin{tabular}{lrrrr}
\hline & \multicolumn{2}{c}{ Levels } & & \% Variations \\
& Mean & SD & Mean & SD \\
\hline Italy & 22.731 & 354 & 0,17 & 0,99 \\
\hline Piedmont & 1.816 & 25 & $-0,02$ & 1,17 \\
Valle d'Aosta & 55 & 1 & $-0,22$ & 0,86 \\
Liguria & 616 & 12 & $-0,28$ & 1,26 \\
Lombardy & 4.281 & 101 & 0,48 & 0,91 \\
Trentino-Alto Adige & 476 & 13 & 0,88 & 0,52 \\
Veneto & 2.099 & 37 & 0,27 & 1,53 \\
Friuli-Venezia Giulia & 504 & 7 & $-0,12$ & 0,98 \\
Emilia-Romagna & 1.946 & 39 & 0,46 & 1,19 \\
Tuscany & 1.558 & 23 & 0,39 & 0,78 \\
Umbria & 356 & 5 & 0,10 & 1,65 \\
Marche & 632 & 12 & $-0,15$ & 1,60 \\
Lazio & 2.274 & 79 & 0,94 & 1,03 \\
Abruzzo & 492 & 10 & 0,03 & 2,06 \\
Molise & 106 & 4 & $-0,15$ & 2,73 \\
Campania & 1.612 & 42 & $-0,29$ & 2,02 \\
Apulia & 1.211 & 37 & $-0,24$ & 2,43 \\
Basilicata & 187 & 4 & $-0,13$ & 2,12 \\
Calabria & 546 & 22 & $-0,58$ & 2,38 \\
Sicily & 1.390 & 51 & $-0,67$ & 1,72 \\
Sardinia & 575 & 17 & $-0,18$ & 2,62 \\
\hline & & & & \\
\hline
\end{tabular}

Some useful insights about the regional dynamics of GDP and employment are obtained from the correlations between the regional series 2009-19. For each region we compute the indices of Bravais-Person wrt the other 19 regions and Table 3 reports their mean. We neglect the presence of negative values, by focusing on absolute values. In the first row of Table 3 we compute the national figure, obtained as average of the 20 correlation indices between the national series and the 20 regional ones.

\footnotetext{
${ }^{12}$ When referring to macro-areas, we adopt the standard aggregation approach, according to which, proceeding from top to bottom in Table 1, Northern regions are the top 8, the Central section includes the following 4 and the bottom 8 regions are the Southern ones.
} 
From a glance at the two pairs of columns in Table 3, it turns out that the pair-wise correlation averages between the regional series of real GDP per capita are much higher than employment ones. Employment seems more heterogeneously distributed than GDP per capita both across regions and for each region wrt the national level.

Table 3. Average correlations, yearly data, 2008-2019

\begin{tabular}{lcc}
\hline & Employment & GDP per capita \\
\hline Italy & 0,62 & 0,84 \\
\hline Piedmont & 0,65 & 0,78 \\
Valle d'Aosta & 0,56 & 0,64 \\
Liguria & 0,59 & 0,80 \\
Lombardy & 0,45 & 0,81 \\
Trentino-Alto Adige & 0,43 & 0,35 \\
Veneto & 0,60 & 0,70 \\
Friuli-Venezia Giulia & 0,64 & 0,77 \\
Emilia-Romagna & 0,49 & 0,68 \\
Tuscany & 0,48 & 0,80 \\
Umbria & 0,55 & 0,78 \\
Marche & 0,55 & 0,82 \\
Lazio & 0,46 & 0,69 \\
Abruzzo & 0,55 & 0,68 \\
Molise & 0,65 & 0,71 \\
Campania & 0,48 & 0,77 \\
Apulia & 0,64 & 0,79 \\
Basilicata & 0,45 & 0,42 \\
Calabria & 0,61 & 0,70 \\
Sicily & 0,59 & 0,68 \\
Sardinia & 0,62 & 0,78 \\
\hline
\end{tabular}

To ease the interpretation of the regional elasticities across periods, we will mildly depart from the prevailing literature and refer to

$$
R E_{i t}=\% X_{i t} /\left|\% X_{N t}\right|
$$

thus expressing in absolute value the denominator of the regional elasticities. Clearly, positive (negative) values indicate an increase (decrease) of the relevant variable in the $i$-region, whereas greater (lower) values than $|1|$ reveal that the intensity of the regional performance is larger (smaller) than the national one. Tables 4 and 5 collect the regional 
elasticities REs of GDP per capita and employment, respectively, during recessions and recoveries (descent and ascent).

Table 4. RE, GDP per capita, 2008-19

\begin{tabular}{lrrrr}
\hline & $\mathrm{a}_{1}$ & \multicolumn{1}{c}{$\mathrm{A}_{1}$} & \multicolumn{1}{c}{$\mathrm{a}_{2}$} & \multicolumn{1}{c}{$\mathrm{A}_{2}$} \\
& $2008 / 09$ & $2010 / 11$ & $2012 / 14$ & $2015 / 19$ \\
Italy & $-1,00$ & 1,00 & $-1,00$ & 1,00 \\
\hline & & & & \\
Piedmont & $-1,54$ & 2,53 & $-1,09$ & 1,35 \\
Valle d'Aosta & $-0,83$ & 2,76 & $-1,38$ & 0,46 \\
Liguria & $-0,93$ & $-0,21$ & $-0,76$ & 0,85 \\
Lombardy & $-0,85$ & 2,22 & $-1,05$ & 1,07 \\
Trentino-Alto Adige & $-0,63$ & 1,60 & $-0,14$ & 0,86 \\
Veneto & $-1,21$ & 1,69 & $-0,77$ & 1,18 \\
Friuli-Venezia Giulia & $-1,46$ & 2,44 & $-0,93$ & 1,16 \\
Emilia-Romagna & $-1,31$ & 1,75 & $-0,62$ & 1,18 \\
Tuscany & $-0,88$ & 0,46 & $-0,59$ & 0,85 \\
Umbria & $-1,39$ & $-0,16$ & $-1,68$ & 1,24 \\
Marche & $-1,17$ & 0,37 & $-0,80$ & 0,70 \\
Lazio & $-0,99$ & $-0,45$ & $-1,92$ & 0,60 \\
Abruzzo & $-0,88$ & 3,31 & $-0,92$ & 0,31 \\
Molise & $-1,03$ & $-1,07$ & $-2,22$ & 1,17 \\
Campania & $-0,87$ & $-2,17$ & $-0,98$ & 0,83 \\
Apulia & $-1,03$ & 1,04 & $-0,74$ & 1,05 \\
Basilicata & $-1,18$ & 0,37 & $-0,75$ & 2,20 \\
Calabria & $-0,63$ & $-0,73$ & $-1,34$ & 0,48 \\
Sicily & $-0,79$ & $-1,40$ & $-1,31$ & 0,48 \\
Sardinia & $-0,57$ & $-0,11$ & $-1,04$ & 0,90 \\
\hline \multicolumn{1}{c}{ Mean } & $-1,01$ & 0,71 & $-1,05$ & 0,95 \\
& 0,27 & 1,49 & 0,47 & 0,41 \\
\hline
\end{tabular}

The first row in Table 4 (5) shows the weighted average of regional GDP per capita (employment), which is worth 1 by construction, while the last but one row reports the simple arithmetic mean.

Notice that during recessions, the sign of the country's row in Table 4 is negative by definition of recessionary shock, while by the same token it is positive during recoveries. A negative sign of the regional elasticities during recoveries $\left(A_{1}\right.$ and $\left.A_{2}\right)$ in Table 4 indicates a countercyclical pattern of the corresponding region wrt the national 
one. Counter-cyclical regions during recessions (see the signs of $\mathrm{a}_{1}$ and $\mathrm{a}_{2}$ ) have not been observed.

Table 5. RE, employment, yearly data, 2008-19

\begin{tabular}{lcc}
\hline & $\mathrm{e}_{1}$ & $\mathrm{E}_{1}$ \\
& $2008 / 13$ & $2014 / 19$ \\
Italy & $-1,00$ & 1,00 \\
\hline & & \\
Piedmont & $-0,64$ & 0,43 \\
Valle d'Aosta & $-0,04$ & $-0,07$ \\
Liguria & $-0,64$ & 0,23 \\
Lombardy & $-0,76$ & 1,61 \\
Trentino-Alto Adige & 0,96 & 1,72 \\
Veneto & $-0,49$ & 1,63 \\
Friuli-Venezia Giulia & $-1,36$ & 0,63 \\
Emilia-Romagna & $-0,17$ & 1,17 \\
Tuscany & $-0,95$ & 1,10 \\
Umbria & $-1,19$ & 0,75 \\
Marche & $-0,99$ & 0,57 \\
Lazio & $-0,32$ & 1,39 \\
Abruzzo & $-0,36$ & $-0,03$ \\
Molise & $-2,57$ & 0,71 \\
Campania & $-2,81$ & 0,68 \\
Apulia & $-1,50$ & 0,99 \\
Basilicata & $-2,80$ & 1,53 \\
Calabria & $-2,01$ & $-0,51$ \\
Sicily & $-2,19$ & $-0,11$ \\
Sardinia & $-1,49$ & 0,81 \\
\hline \multicolumn{1}{c}{ Mean } & $-1,12$ & 0,76 \\
& 0,97 & 0,63 \\
\hline
\end{tabular}

Since the employment is not synchronized with GDP per capita, we obtain a different time scanning of recessions and descent-ascent (Tables 4 and 5). A negative (positive) regional $\mathrm{RE}_{\mathrm{i}}$ means that employment in the $i$-th region is decreasing (increasing). Note that a positive $\mathrm{RE}_{\mathrm{i}}$ during the descent phase $\left(\mathrm{e}_{1}\right)$ or a negative $\mathrm{RE}_{\mathrm{i}}$ during the ascent phase $\left(\mathrm{E}_{1}\right)$ indicates that the regional employment is moving in the opposite direction wrt the national employment. 
Some remarks are in order. First of all, the regional employment (Table 5), except in the two years 2010-11, is always more heterogeneously reacting than regional GDP per capita (Table 4), as it is apparent from the values of the SD, revealing also that, across periods, the range of the regional GDP' SD is smaller than the employment's one.

Moreover, Italian regions differ in their GDP resilience, but, for the first recession, such differences mainly concern the recovery period to the shock and not so much the resistance stage. During both recessions, all regions experience a fall in GDP ( $a_{1}$ and $\mathrm{a}_{2}$ are never positive) with a modest variability across regions ( $\mathrm{SD}=0.27$ and 0.47 , respectively), although $\mathrm{a}_{1}$ ranges from -1.54 in Piedmont to - 0.57 in Sardinia, and $\mathrm{a}_{2}$ from - 2.22 in Molise to - 0.14 in Trentino (Table 4). As for GDP per capita, Trentino is the most resilient territory.

As for employment (Table 5), only Trentino exhibits a positive value of $\mathrm{e}_{1}$, meaning that its employment level rises, while the Southern regions (particularly Campania) perform much worse than the average ${ }^{13}$.

In order to check the robustness of our results with respect to the regional size, in Tables 4A and 5A we report the REs for GDP and employment, respectively, eliminating the region under scrutiny from the denominator. Most of the values vary mildly, although for the largest regions the gap is not negligible. The resilience of Campania's employment, for instance, in the first descent is about 2,8 times lower than the national one (Table 5), but it is 3,3 times lower than the rest of the country (Table 5A). The Lombardia's GDP, instead, in the first recovery is more than twice as resilient as the whole country, but it is almost 3.5 times as resilient when compared with the rest of the country. We will come back to Tables $4 \mathrm{~A}$ and 5A when checking the robustness of our results (Section 5).

\footnotetext{
${ }^{13}$ In Cellini et al. (2017, p. 8), all regions experience a fall in both GDP per capita and employment during the 2008-9 recession. This is likely due to the different scan of their time frame.
} 
We now summarize in Table 6 our measures of resilience. We obtain Resistance as the sum of $\mathrm{a}_{1}$ and $\mathrm{a}_{2}$ for GDP, while $\mathrm{e}_{1}$, as we know, indicates the regional elasticity of employment during descent. Similarly, we compute Recovery for GDP $\left(\mathrm{A}_{1}\right.$ and $\left.\mathrm{A}_{2}\right)$, while $\mathrm{E}_{1}$ measures the regional resilience of employment during ascent. Finally, Total resilience results by adding the values of Resistance (Descent) and Recovery (Ascent) for GDP (Employment). This choice of measuring total resilience may be justified on the basis of the following arguments. Concerning employment, first of all, the periods of descent and ascent last an equal number of 6 years. Moreover, the size of both national descent and ascent are very close. As a consequence, the sum of $e_{1}$ and $E_{1}$ yields values of the employment total resilience unaffected by the mild variation in national employment along our time span. Similar arguments apply to GDP per capita, although $A_{1}$ and $A_{2}$ refer to different length periods and in the second recovery the GDP uplifts much more than in the first one.

Let us focus on total resilience.

Employment. Lazio, Trentino-Aldo Adige and Emilia-Romagna present the best performance. As for Lazio, this outcome seems driven by its striking resistance: a value of - 0,32 means that its employment fell by less than one third wrt the national fall. This is not so surprising, given the high share of employees in the public sector. We will come back to the role of public sector employees in the next section.

GDP per capita. The top 3 regions are now Abruzzo, which ranks second in recovery (just behind Piedmont), Trentino-Alto Adige and Lombardy.

Southern regions display a much poorer performance than the other 12 regions, especially in terms of employment. The well-documented territorial divide is confirmed once again (Bank of Italy, 2015, Di Caro 2018, inter alia). 
Table 6. Resilience: resistance, recovery, total

\begin{tabular}{lcc|cc|cc}
\hline Regions & \multicolumn{2}{c|}{ Descent-Resistance } & \multicolumn{2}{c|}{ Ascent-Recovery } & \multicolumn{2}{c}{ Total resilience } \\
& Employment & GDP & Employment & GDP & Employment & GDP \\
\hline & $\mathrm{e}_{1}$ & $\mathrm{a}_{1}+\mathrm{a}_{2}$ & $\mathrm{E}_{1}$ & $\mathrm{~A}_{1}+\mathrm{A}_{2}$ & $\mathrm{e}_{1}+\mathrm{E}_{1}$ & $\mathrm{~A}_{1}+\mathrm{A}_{2}$ \\
$+\mathrm{a}_{1}+\mathrm{a}_{2}$ \\
\hline
\end{tabular}

In Figures $2 \mathrm{~A}, 3 \mathrm{~A}$ and $4 \mathrm{~A}$ we draw the maps for resistance, recovery and total resilience, respectively. As for the employment, the pictures do not significantly differ from the ones in Di Caro (2015, pp. 24-5), notwithstanding the different time scan of recessions. In resistance as well as in recovery periods, the regions in the Centre-North, especially along the Adriatic belt, look more resilient than the Southern regions.

Notice that, differently from the finding in Fingleton et al. (2012) for a group of UK regions during and after earlier recessions, here the impact of the recessionary downturns on regional economies is not a good predictor of the size of the recovery. Indeed, we observe a low correlation between regional elasticities in resistance and in 
recovery of GDP as well employment, for both recessions and the descent occurred in our time frame ${ }^{14}$.

\section{Cooperatives and economic resilience}

In view of a better understanding of the economic forces driving the regional resilience computed and illustrated before, we focus on the size of the cooperative movement, as summarized by two variables: (i) the ratio between the added value of cooperative firms and the regional GDP, and (ii) the ratio between the workforce employed in cooperatives and the overall regional employment.

While the database about some variables to be used is still borrowed from Istat, the additional dataset on the cooperatives is retrieved from the platform Madh (Market Access Data Hub) made by the Emilia-Romagna Union of Chambers of Commerce (Unioncamere) which includes, among the many information sets, the balance sheets of all Italian companies ${ }^{15}$. Unfortunately, this dataset is available (yearly) only since 2010 and this constraint shrinks the length of our time series as compared to other analyses of the resilience of Italian regions ${ }^{16}$.

Table 7 reports the descriptive statistics of both (i) and (ii). The cooperative movement is clearly distributed unevenly across Italian regions and it is mostly concentrated in the Centre-North, with Emilia-Romagna ranking first in terms of employment as well as added value. Moreover, the employment ratio is always superior to the added value to the GDP one. The importance of the cooperative employment is further strengthened

\footnotetext{
14 The full set of pair-wise Pearson's coefficients between $a_{1}, a_{2}, e_{1}, A_{1}, A_{2}, E_{1}$, and between all (variables in the) columns of Table 6 is available upon request.

${ }^{15}$ For each registered company, the dataset draws information from the Register of firms as recorded in the Chambers of Commerce, Inps, Minister of the Economic Development (MISE), Aida-Bureau van Dijk (containing balance sheets of companies and business groups), Istat and other sources.

16 The data regarding the period 2007-9 have been estimated using sample information provided by the three major cooperative associations.
} 
in some regions already featuring a high cooperative presence, as Emilia-Romagna and Trentino-Alto Adige, given that our data do not include the insurance and financial sectors $^{17}$.

Table 7. Descriptive statistics, cooperative added value and employment, yearly data, 2008-2019

\begin{tabular}{l|rrrr|rrrr}
\hline & \multicolumn{3}{|c|}{ Coop. Added Value / GDP } & \multicolumn{4}{c}{ Coop. Employment / Empl. } \\
\hline & Mean & \multicolumn{1}{|c}{ SD } & min & $\max$ & Mean & SD & min & Max \\
\hline Piedmont & 1,34 & 0,08 & 1,11 & 1,41 & 3,66 & 0,45 & 2,62 & 4,01 \\
Valle d'Aosta & 1,01 & 0,09 & 0,85 & 1,14 & 2,70 & 0,57 & 1,74 & 3,45 \\
Liguria & 1,23 & 0,06 & 1,06 & 1,30 & 3,20 & 0,60 & 2,17 & 3,71 \\
Lombardy & 1,08 & 0,08 & 0,94 & 1,17 & 3,60 & 0,76 & 2,25 & 4,18 \\
Trentino-Alto Adige & 2,32 & 0,30 & 1,74 & 2,59 & 4,84 & 0,54 & 3,66 & 5,33 \\
Veneto & 1,28 & 0,11 & 1,04 & 1,39 & 3,25 & 0,62 & 2,11 & 3,80 \\
Friuli-Venezia Giulia & 1,49 & 0,08 & 1,32 & 1,64 & 3,88 & 0,65 & 2,62 & 4,68 \\
Emilia-Romagna & 5,66 & 0,21 & 5,22 & 5,88 & 11,69 & 0,94 & 9,79 & 12,61 \\
Tuscany & 2,01 & 0,09 & 1,90 & 2,15 & 4,30 & 0,53 & 3,23 & 4,75 \\
Umbria & 3,31 & 0,36 & 2,69 & 4,18 & 5,67 & 0,71 & 4,46 & 6,72 \\
Marche & 1,35 & 0,11 & 1,07 & 1,48 & 2,92 & 0,59 & 1,58 & 3,40 \\
Lazio & 1,11 & 0,09 & 0,98 & 1,23 & 4,15 & 1,02 & 2,42 & 5,24 \\
Abruzzo & 0,79 & 0,06 & 0,68 & 0,89 & 2,24 & 0,60 & 1,10 & 2,74 \\
Molise & 0,93 & 0,18 & 0,66 & 1,44 & 2,81 & 0,58 & 1,76 & 3,57 \\
Campania & 0,86 & 0,07 & 0,76 & 0,96 & 2,77 & 0,81 & 1,39 & 4,07 \\
Apulia & 1,14 & 0,07 & 0,99 & 1,23 & 3,86 & 1,13 & 2,12 & 6,18 \\
Basilicata & 0,93 & 0,12 & 0,64 & 1,06 & 2,82 & 0,69 & 1,46 & 3,60 \\
Calabria & 0,55 & 0,04 & 0,46 & 0,58 & 2,05 & 0,31 & 1,46 & 2,34 \\
Sicily & 0,86 & 0,04 & 0,78 & 0,92 & 3,01 & 0,90 & 1,57 & 4,86 \\
Sardinia & 1,47 & 0,03 & 1,42 & 1,52 & 3,47 & 0,76 & 2,11 & 4,12 \\
& & & & & & & & \\
\hline
\end{tabular}

Together with the measuring of the resilience across Italian regions, we also aim to the development of explanations of which factors contribute to strengthen it. Regarding the resilience of regional employment, as suggested in other related papers (e.g., Groot et al. (2011), Lagravinese (2015) and Martin et al. (2016)), we consider the composition of employment. More precisely, we focus on the average (in the periods)

\footnotetext{
17 The diffusion of cooperative banks in terms of employees is visualized in Figure 5A, which is obtained by elaborating data of Bank of Italy (2021) referred to 2019.
} 
shares of employees out of total employment, in the industrial and in the public sector ${ }^{18}$ ( $X i$, and $X p$, respectively). Moreover, to disentangle the regional elasticities of employment ( $R E \mathrm{emp}$ ), we consider also the average (in the relevant periods) of the cooperative share of total regional employment $(X c)$. As for the regional elasticities of GDP per capita ( $R E g d p$ ), instead, we concentrate on the average (in the periods) share of cooperative added value out of total regional GDP $(X g)$.

Table 8. Descriptive statistics, resilience (employment and GDP) and explanatory variables, yearly data, 2008-2019

\begin{tabular}{lrrrrrr}
\hline & $R E$ emp & $R E g d p$ & $X i$ & $X p$ & $X c$ & $X g$ \\
\hline Mean & $-0,35$ & $-0,40$ & 0,22 & 0,21 & 0,04 & 0,02 \\
Median & $-0,41$ & 0,08 & 0,22 & 0,21 & 0,03 & 0,01 \\
SD. & 1,30 & 1,77 & 0,06 & 0,03 & 0,02 & 0,01 \\
Min & $-2,52$ & $-3,20$ & 0,13 & 0,15 & 0,02 & 0,01 \\
Max & 2,68 & 1,83 & 0,32 & 0,27 & 0,12 & 0,06 \\
& & \multicolumn{7}{c}{ Total } \\
Mean & $-1,11$ & $-2,06$ & 0,24 & 0,21 & 0,03 & 0,02 \\
Median & $-0,97$ & $-1,95$ & 0,23 & 0,21 & 0,03 & 0,01 \\
SD & 0,99 & 0,57 & 0,06 & 0,04 & 0,02 & 0,01 \\
Min & $-2,08$ & $-3,25$ & 0,14 & 0,15 & 0,02 & 0,01 \\
Max & 0,96 & 0,78 & 0,35 & 0,27 & 0,10 & 0,06 \\
& & \multicolumn{7}{c}{ Recovery (Ascent) } \\
Mean & 0,76 & 1,66 & 0,21 & 0,21 & 0,04 & 0,02 \\
Median & 0,73 & 1,70 & 0,21 & 0,21 & 0,04 & 0,01 \\
SD & 0,64 & 1,61 & 0,06 & 0,03 & 0,02 & 0,01 \\
Min & $-0,51$ & $-1,34$ & 0,11 & 0,15 & 0,02 & 0,01 \\
Max & 1,72 & 3,88 & 0,30 & 0,27 & 0,11 & 0,06 \\
\hline
\end{tabular}

In Table 8 we report the descriptive statistics of all resilience indices and the explanatory variables to be used. It is worth noting that the regional elasticity of employment are much more heterogeneous than the one about GDP in all time periods (as it emerged also in Tables 4 and 5). Looking at the first two columns, one notices that the mean and the median share the same sign except in the case dealing with total

\footnotetext{
${ }^{18}$ Notice that $\mathrm{Xi}$ (which includes employees in the manufacturing and construction sectors) may include also, in some regions, workers operating in cooperative firms.
} 
resilience in terms of GDP. The mean is negative and strongly affected by the pattern of some Southern regions, whereas the median is moderately positive.

\section{Results}

In this section we test the relationship between two dimensions of economic resilience (resistance and recovery) and the size of the cooperative movement, as summarized by the employment and the added value.

To assess the presence of such a relationship we employ a simple linear model regressing regional resilience in its three senses of resistance, recovery and total, as reported in Table 6. Hence, we spell out six simple models: three regarding the resilience of employment and three for the one of GDP. To consider the well-known territorial dualism featuring the Italian regions, in addition to $X i, X p, X c$ e $X g$, we include also a dummy $S$ featuring the 8 Southern regions.

For each model we formulate a different specification, from the simplest ones (based on a unique explanatory variable), to the most complete model including jointly all considered variables.

We now summarize the most interesting findings emerging from our analysis. The first one deals with the total resilience $\left(e_{1}+E_{l}\right)$ of regional employment (last but one column in Table 6). Hence, we are now considering the entire time span 2008-19.

The OLS estimate indicates a significant effect only for the cooperative employment $X c$ and the dummy $S$. Among the various specifications that we have considered, the one which detects a significant relationship is the following:

$\left(e_{1}+E_{1}\right)_{i}=\beta_{0}+\beta_{1} X c_{i}+\beta_{2} S_{i}+\varepsilon_{i}$ 
The results are reported in the first column of Table 9, the robust standard errors (in brackets) are calculated by means of the Arellano HAC estimator because of the presence of heteroskedasticity.

The value of the parameter for $X c$ suggests a positive impact of the cooperative employment on total resilience of regional employment. The value of the parameter for $S$ captures the negative differential in total resilience of the employment in Southern regions.

Table 9 - OLS estimates, Italian regional resilience, 2008-2019

\begin{tabular}{llllll}
\hline Dep. Var. & $\left(e_{1}+E_{1}\right)$ & $e_{1}$ & $e_{1}$ & $E_{1}$ & $E_{1}$
\end{tabular}

\begin{tabular}{lrrrrr}
\hline$X p$ & - & - & - & & $-9,573$ \\
& & & & & $(3,180)$ \\
$X c$ & 12,619 & 20,423 & 4,751 & 12,123 & - \\
& $(5,641)$ & $(8,507)$ & $(3,516)$ & $(6,674)$ & \\
$S$ & $-1,646$ & - & $-1,342$ & - & - \\
& $(0,424)$ & & $(0,341)$ & & \\
\hline $\mathrm{R}^{2}$ & 0,534 & 0,145 & 0,522 & 0,138 & 0,247 \\
$\mathrm{RSS}$ & 14,95 & 16,00 & 8,95 & 6,76 & 5,90 \\
Test F & 12,643 & 5,767 & 8,25 & 3,300 & 9,065 \\
$\mathrm{p}$-value(F) & 0,0004 & 0,027 & 0,003 & 0,086 & 0,008 \\
\hline Robst
\end{tabular}

Robust standard errors in brackets.

Another result worth commenting emerges from the model testing the regional resilience of employment during the ascent period 2014-19. In this case, we focus on specifications in which both $X p$ and $X c$ are singularly considered:

$\left(E_{1}\right)_{i}=\beta_{0}+\beta_{I} X p_{i}+\varepsilon_{i}$

$\left(E_{1}\right)_{i}=\beta_{0}+\beta_{1} X c_{i}+\varepsilon_{i}$ 
In the last two columns of Table 9 we report the OLS estimates. In both equations, $X p$ and $X c$ are significantly contributing to explain the employment resilience in ascent. As for the cooperative employment, the positive effect is confirmed, whereas the public sector employment operates counter-cyclically. This last effect can be interpreted as a weaker participation to recovery (ascent) for regions featured by a major presence of public employees. In either case, the dummy stops being significative, suggesting that recoveries have been about all regions without relevant territorial divides.

During the descent, as opposed to some empirical evidence ${ }^{19}$, the model does not fully support an anti-cyclical role of the cooperative employment, possibly because of the severity of downturns and their widespread diffusion on the national territory. More precisely, by looking at $X c$ only, we test the following:

$\left(e_{1}\right)_{i}=\beta_{0}+\beta_{1} X c_{i}+\varepsilon_{i}$

and, from the results reported in Table 9 (second column), we find a positive effect; however, including the South dummy, that is by evaluating

$\left(e_{1}\right)_{i}=\beta_{0}+\beta_{I} X c_{i}+\beta_{2} S_{i}+\varepsilon_{i}$

$X c$ stops being significant (Table 9, third column).

To check the robustness of the results collected in Table 9, we replicate our analysis using the values of regional elasticities obtained by eliminating the region under scrutiny from the denominator. In other words, we pick the dependent variables from Tables 4A and 5A instead of Table 6. Our previous findings are basically confirmed as we still detect a positive and significant effect of cooperative employment on total resilience of regional employment as well as during the ascent. Unsurprisingly, the

\footnotetext{
${ }^{19}$ On such counter-cyclical role in increasing jobs in the aftermath of crises, see Borzaga et al. (2021) and OECD (2021). See also Caselli et al. (2021) and the bibliography there cited.
} 
elimination of the "relevant" region from the national benchmark yields a minor role of the South dummy chich stops being significant.

It is also worth stressing that the cooperative presence matters in terms of employment, but not in terms of the impact of its added value on GDP per capita. This evidence is assessed by testing the following three models ${ }^{20}$ :

$\left(A_{1}+A_{2}+a_{1}+a_{2}\right)_{i}=\beta_{0}+\beta_{1} X g_{i}+\varepsilon_{i}$

$\left(a_{1}+a_{2}\right)_{i}=\beta_{0}+\beta_{1} X g_{i}+\varepsilon_{i}$

$\left(A_{1}+A_{2}\right)_{i}=\beta_{0}+\beta_{1} X g_{i}+\varepsilon_{i}$

We do not observe a significant role for the cooperative added value, since the parameter $\beta_{l}$ is never significantly different from zero. This not surprising, for a large portion of Italian cooperatives operate in labor-intensive sectors featured by a relatively low added-value per worker. In 2015, for instance, the average added value per worker was 45,605 euros in the overall Italian companies, whereas in the cooperative subset of them was only 24,851 euros $^{21}$. The massive presence of cooperative enterprises in labor-intensive sectors nation-wide actually emerges also from the gap between their weight in terms of added valued and the one in terms of employment. According to Istat (2019), in 2015, including subsidiaries, the cooperative companies account for about 1,215,000 employees (7.4\% of total employment in the Italian private sector) and over 32 billion euros (4.4\% of the corresponding added value). Therefore, this gap looks like a convincing explanation of the significantly positive impact of the cooperative employment on regional resilience of employment wrt the non-significant impact of cooperative added value on the resilience of regional GDP per capita.

\footnotetext{
${ }^{20}$ These models are simpler than those tested for employment, as they focus exclusively on the share of cooperative GDP; this is because the computation of the added value for public sectors' activities is notoriously at odds with the one for other sectors.

${ }^{21}$ Borzaga et. al. (2019). These figures exclude financial and insurance activities.
} 
Moreover, we believe that an even deeper explanation for the cooperative contribution to resilience lies in its democratic governance ${ }^{22}$. This is especially true for production cooperatives, i.e., enterprises owned and managed by working-members. Such cooperatives tend to protect employees even at the cost of sacrificing profits. In this respect, the cooperative movement belongs to the civic capital of a territory ${ }^{23}$.

Furthermore, on the theoretical grounds, the observed behavior of production cooperatives can hardly be rationalized as a "perverse" effect within the traditional formulation of Ward (1958), according to which cooperatives maximize the net revenue per member. The actual strategies of such enterprises seem driven by a maximand including both employees (especially working members) and profits, with the former weighting more than the latter in recessionary times ${ }^{24}$.

\section{Concluding remarks}

In this paper we have investigated and compared two key dimensions of economic resilience (resistance and recovery) in terms of GDP per capita as well as employment for all Italian regions in the period 2008-19. In addition to allow an update of similar studies on the resilience of Italian regions, our analysis delivers a new insight in explaining the large heterogeneity featuring the reactions of Italian regions during and after recessionary episodes. We have treated our regional elasticities as variables depending also on a sizeable socio-economic phenomenon like the Italian cooperative movement and, in short, the novel evidence points to the cooperative employment as

\footnotetext{
${ }^{22}$ On the UK experience about the organizational resilience of employee owned companies, see Lampel et al. (2014).

${ }^{23}$ See Barrios et. al. (2020). See also Cellini and Cuccia (2019) on the relationship between economic resilience and cultural behavior across Italian regions.

24 This is what apparently emerges from an empirical research on the world most important cooperative district by Caselli et al. (2021) where one finds also a discussion of the relevant literature.
} 
positively associated with the regional resilience when measured in terms of employment.

Recent empirical studies ${ }^{25}$ have identified some weaknesses of cooperative enterprises as the uneasy access to the banking and financial markets, especially for smaller companies (most of them also late in digitalization), and a productivity handicap wrt to profit-making competitors.

Since both the ability to absorb (resistance) and to bounce-back (recovery) are desirable features of territorial systems, we may then argue that a large cooperative presence provides a comparative advantage to promote prosperity and protect it during and/or after downturns ${ }^{26}$. We may also claim that a strong cooperative movement seems representing a meaningful driver of the $8^{\text {th }}$ SDG (inclusive growth), as well as a potentially powerful instrument to be utilized in implementing the EU Recovery and Resilience Program.

Hence, the cooperative one seems a socially meritorious organizational form to be promoted and strengthened with national as well as regional policies ${ }^{27}$. Of course, policies need to be place-based, to consider the differences across regional economic systems and/or across sectors ${ }^{28}$. Tailored-made policy instruments designed to mitigate such comparative handicaps might enhance welfare in the local communities.

\footnotetext{
${ }^{25}$ For instance, Amorato (2017), Borzaga et al. (2019), Istat (2019), Cori et al. (2021), OECD (2021). For an exhaustive historical account of the problems faced by the cooperative form, and some policy directions, see Dow (2018).

${ }^{26}$ In Costa et al. (2021) it is shown that in Italy the size of cooperative employment is positively associated to an index of regional prosperity which considers both household's disposable income and its distribution across households.

${ }^{27}$ Incidentally, a special attention to cooperatives in Italy is established in art. 45 of the Constitution. The insightful report by OECD (2021) confirms the many interdependencies between cooperative organizations and local communities. See also Cecop (2012).

${ }^{28}$ It is worth noting that some Italian industries (e.g., logistics) feature cooperatives qualified as spurious, i.e., fake. Such firms are established to underpay workers, circumvent rules and are prone to frequent bankruptcies in order to avoid controls by authorities and circumvent fiscal compliance.
} 
Cooperatives seem also able to make the employment of their communities more resilient, as we have tried to show. Therefore, we may cautiously endorse the OECD view $(2021$, p. 1) that cooperatives "in a post pandemic world could make a major contribution to steering the economy towards inclusiveness and sustainability". 


\section{Appendix}

Figure 1A. Employment and GDP per capita $(2007=100)$, gray bands indicate recessions

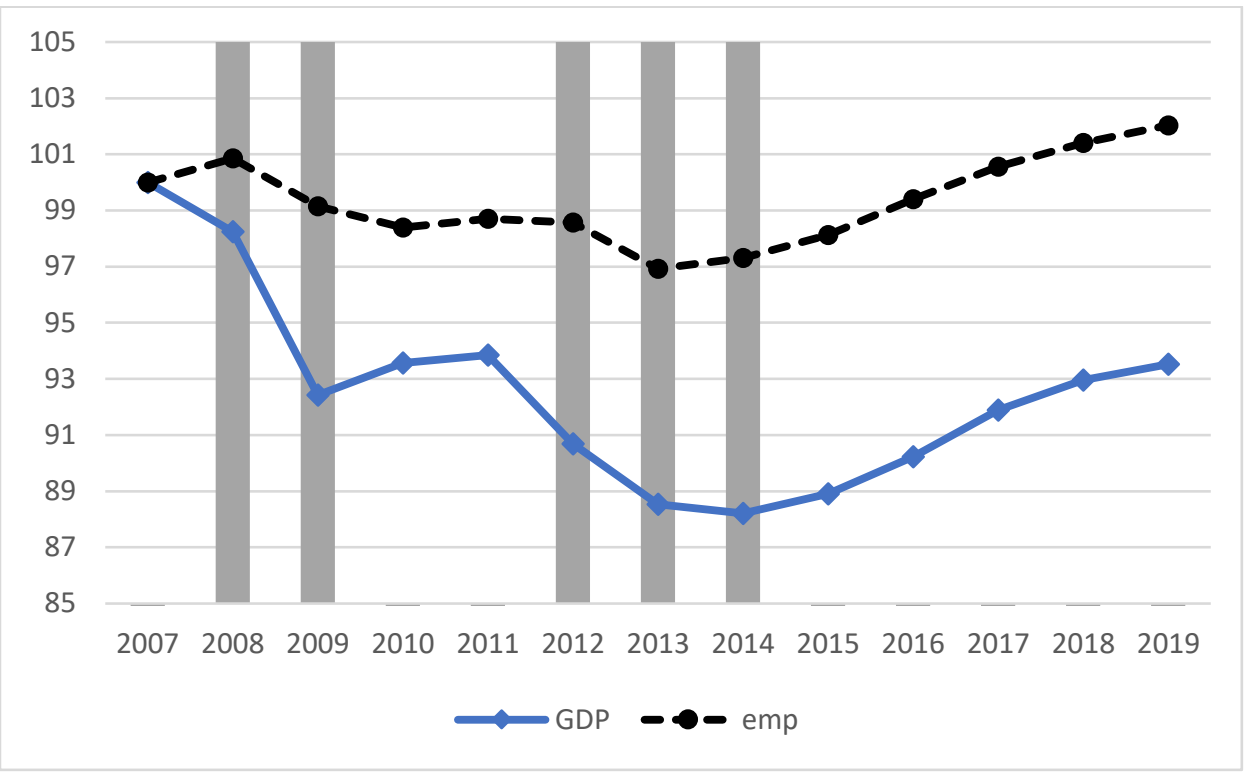

Table 4A. RE.i, GDP per capita, 2008-19

\begin{tabular}{|c|c|c|c|c|}
\hline Italy & $\begin{array}{c}a_{1} \\
2008 / 09 \\
-1,00\end{array}$ & $\begin{array}{c}\mathrm{A}_{1} \\
2010 / 11 \\
1,00\end{array}$ & $\begin{array}{c}a_{2} \\
2012 / 14 \\
-1,00\end{array}$ & $\begin{array}{c}\mathrm{A}_{2} \\
2015 / 19 \\
1,00\end{array}$ \\
\hline Piedmont & $-1,61$ & 2,88 & $-1,10$ & 1,39 \\
\hline Valle d'Aosta & $-0,83$ & 2,77 & $-1,39$ & 0,45 \\
\hline Liguria & $-0,93$ & $-0,20$ & $-0,75$ & 0,84 \\
\hline Lombardy & $-0,82$ & 3,46 & $-1,05$ & 1,12 \\
\hline Trentino-Alto Adige & $-0,63$ & 1,63 & $-0,14$ & 0,86 \\
\hline Veneto & $-1,24$ & 1,81 & $-0,75$ & 1,20 \\
\hline Friuli-Venezia Giulia & $-1,48$ & 2,52 & $-0,93$ & 1,17 \\
\hline Emilia-Romagna & $-1,35$ & 1,90 & $-0,60$ & 1,21 \\
\hline Tuscany & $-0,88$ & 0,44 & $-0,57$ & 0,84 \\
\hline Umbria & $-1,39$ & $-0,16$ & $-1,70$ & 1,24 \\
\hline Marche & $-1,18$ & 0,37 & $-0,79$ & 0,70 \\
\hline Lazio & $-0,98$ & $-0,38$ & $-2,15$ & 0,58 \\
\hline Abruzzo & $-0,87$ & 3,47 & $-0,91$ & 0,31 \\
\hline Molise & $-1,03$ & $-1,07$ & $-2,23$ & 1,17 \\
\hline Campania & $-0,86$ & $-1,79$ & $-0,98$ & 0,82 \\
\hline Apulia & $-1,03$ & 1,05 & $-0,73$ & 1,05 \\
\hline Basilicata & $-1,18$ & 0,37 & $-0,75$ & 2,22 \\
\hline Calabria & $-0,62$ & $-0,71$ & $-1,34$ & 0,48 \\
\hline Sicily & $-0,78$ & $-1,24$ & $-1,33$ & 0,47 \\
\hline Sardinia & $-0,56$ & $-0,11$ & $-1,04$ & 0,90 \\
\hline Mean & $-1,01$ & 0,85 & $-1,06$ & 0,95 \\
\hline SD & 0,29 & 1,57 & 0,50 & 0,42 \\
\hline
\end{tabular}


Table 5A. RE-i, Employment, 2008-19

\begin{tabular}{lcc}
\hline & $\mathrm{e}_{1}$ & $\mathrm{E}_{1}$ \\
& $2008 / 09$ & $2010 / 11$ \\
Italy & $-1,00$ & 1,00 \\
\hline & & \\
Piedmont & $-0,63$ & 0,41 \\
Valle d'Aosta & $-0,04$ & $-0,07$ \\
Liguria & $-0,63$ & 0,23 \\
Lombardy & $-0,72$ & 1,87 \\
Trentino-Alto Adige & 0,92 & 1,75 \\
Veneto & $-0,46$ & 1,73 \\
Friuli-Venezia Giulia & $-1,37$ & 0,62 \\
Emilia-Romagna & $-0,16$ & 1,19 \\
Tuscany & $-0,94$ & 1,11 \\
Umbria & $-1,20$ & 0,75 \\
Marche & $-0,99$ & 0,57 \\
Lazio & $-0,29$ & 1,45 \\
Abruzzo & $-0,35$ & $-0,03$ \\
Molise & $-2,59$ & 0,71 \\
Campania & $-3,33$ & 0,66 \\
Apulia & $-1,55$ & 0,99 \\
Basilicata & $-2,85$ & 1,54 \\
Calabria & $-2,06$ & $-0,49$ \\
Sicily & $-2,39$ & $-0,11$ \\
Sardinia & $-1,51$ & 0,81 \\
\hline & $-1,16$ & 0,78 \\
& 1,04 & 0,66 \\
\hline
\end{tabular}

Figure 2A. Resistance (increases according to the color's intensity)
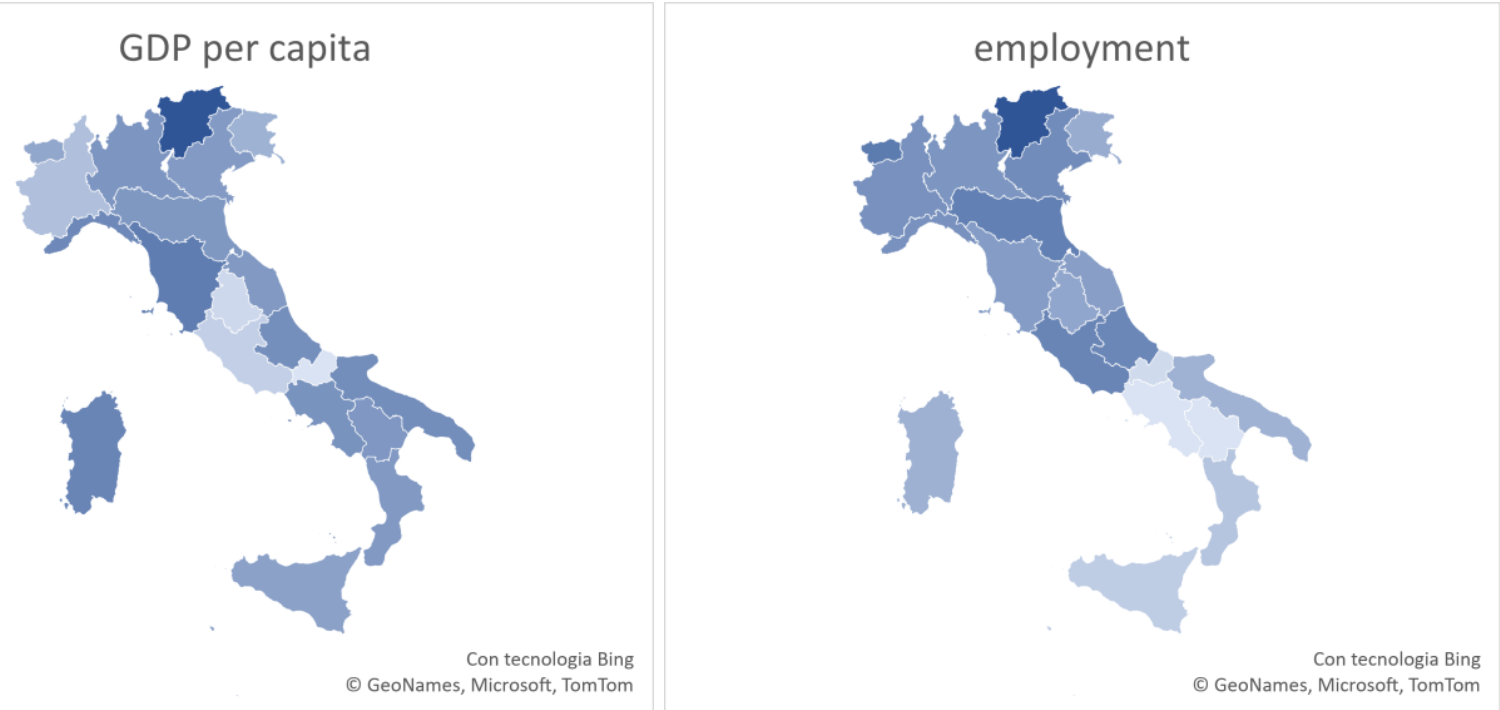
Figure 3A. Recovery (increases according to the color's intensity)
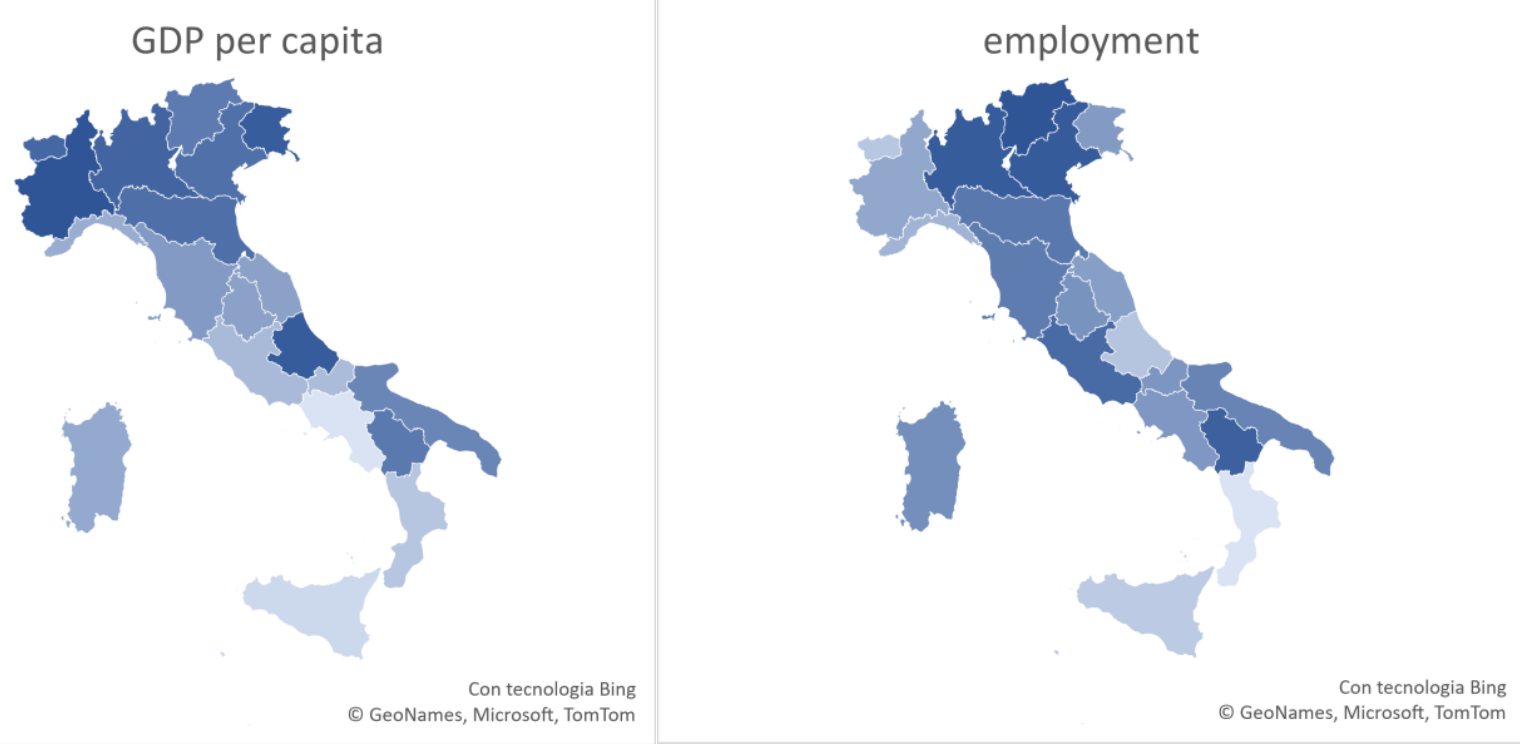

Figure 4A. Total resilience (increases according to the color's intensity)
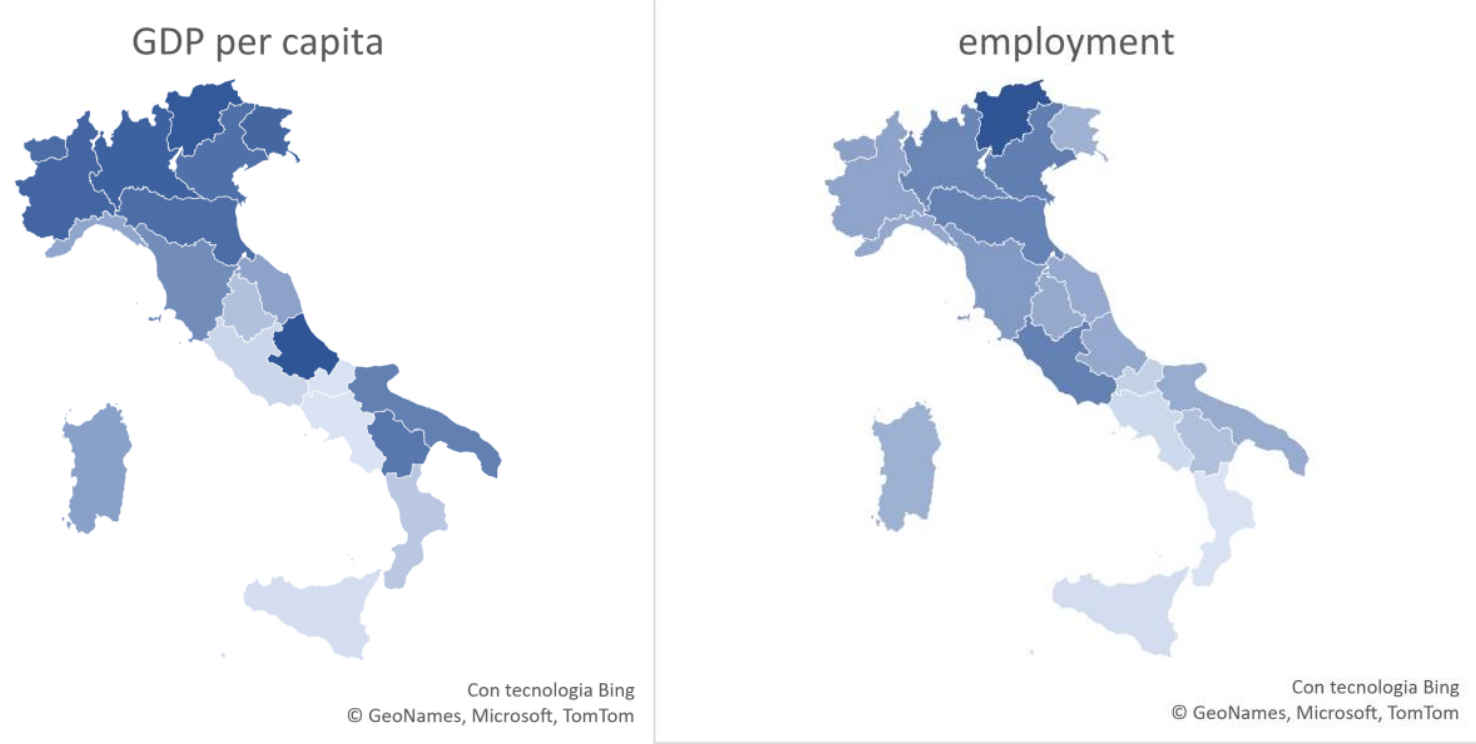
Figure 5A. (a) Cooperative Added Value/GDP; (b) Cooperative Employment/Total Employment; (c) Cooperative Banking Employees. (increases according to the color's intensity)

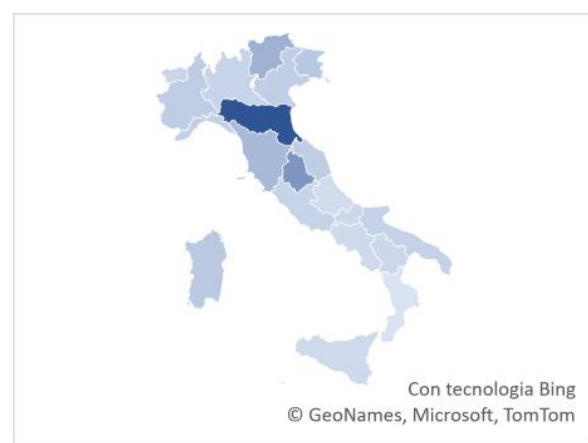

(a)

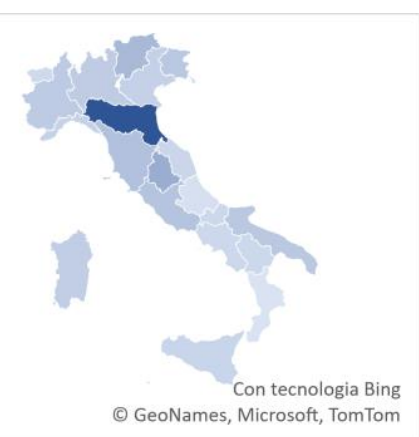

(b)

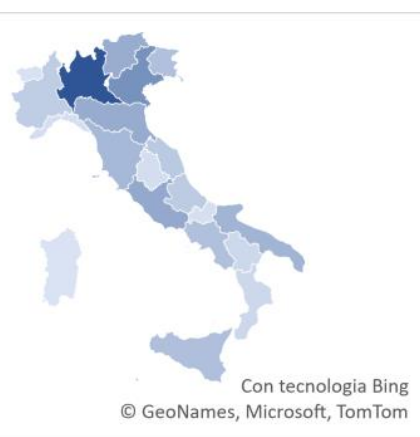

(c) 


\section{References}

Amorato, P. (2018), The Growth of Italian Cooperatives. Innovation, Resilience and Social Responsibility, New York-London, Routledge.

Bank of Italy (2015), Economie regionali. L'economia delle regioni italiane, Rome.

Bank of Italy (2021), Banche e istituzioni finanziarie: articolazione territoriale, Rome.

Barrios, J., E. Benmelech, Y. Hochberg, P. Sapienza and L. Zingales (2020), "Civic Capital and Social Distancing during the Covid-19 Pandemic", NBER WP 27320.

Borzaga, C., M. Calzaroni, C. Carini and M. Lori (2019), "Structure and performance of Italian cooperatives: a quantitative analysis based on combined used of official data”, Journal of Entrepreneurship and Organizational Diversity, 8, 65-83.

Borzaga, C., C. Carini and E. Tortia (2021), "Co-operative enterprise and anticyclicality and the economic crisis: A comparative of employment dynamics in Italy", Annals of Public and Cooperative Economics, DOI: 10.1111/apce.12337.

Cainelli, G., R. Ganau and M. Modica (2019), "Does related variety affect regional resilience? New evidence from Italy", Annals of Regional Science, 62, 657-80.

Caselli, G., M. Costa and F. Delbono (2021), "What Do Cooperative Firms Maximize, if at All? Evidence from Emilia-Romagna in the pre-Covid Decade", WP 1159, Department of Economics, University of Bologna; Annals of Public and Cooperative Economics, forthcoming.

Cecop (2012), The resilience of the cooperative model.

Cellini, R. and T. Cuccia (2019), "Do behaviours in cultural markets affect economic resilience? An analysis if Italian regions”, European Planning Studies, 27, 784-801.

Cellini, R. and G. Torrisi (2014), "Regional resilience in Italy: a very long-run analysis”, Regional Studies, 48, 1179-96.

Cellini, R. P. Di Caro and G. Torrisi (2017), "Regional resilience in Italy: do employment and income tell the same story?", in R. Huggins and P. Thompson (eds.), Handbook of Regions and Competitiveness, Elgaronline, 308-31.

Cori, A., M. Granata, K. Lelo and S. Monni (2021), "Mapping cooperatives in Italy", Entrepreneurship and Sustainability, 8, 136-162. 
Costa, M., F. Delbono and F. Linguiti (2021), "Cooperative Movement and Prosperity across Italian Regions", WP 1161, Dept of Economics, University of Bologna.

Delbono, F. and C. Reggiani (2013), "Cooperative firms and the crisis: evidence from some Italian mixed oligopolies", Annals of Public and Cooperative Economics, 84, 383-97.

Di Caro, P. (2015), "Recessions, Recoveries and Regional resilience: evidence on Italy", Cambridge Journal of Regions, Economy and Society, 8, 273-91.

Di Caro, P. (2018), "To be (or not to be) resilient over time: facts and causes", Annals of Regional Science, 60, 375-92.

Dow, G. (2018), The Labor-Managed Firm. Theoretical Foundations, Cambridge, Cambridge University Press.

Euricse (2013), The Italian cooperative movement during the crisis, in Italian.

Euricse (2020), Exploring the co-operative economy.

Faggian, A., R. Gemmiti, T. Jaquet and I. Santini (2018), "Regional economic resilience: the experience of the Italian labor system", Annals of Regional Science, 60, 393-410.

Fingleton, B., H. Garretsen, and R. Martin (2012), "Recessionary shocks and regional employment: Evidence on the resilience of UK regions", Journal of Regional Science, $52,109-33$.

Fingleton, B., H. Garretsen, and R. Martin (2015), "Shocking aspects of Monetary Union: the vulnerability of regions in Euroland", Journal of Economic Geography, 15, 907-34.

Fratesi, U., and G. Perucca (2018), "Territorial capital and the resilience of European regions", Annals of Regional Science, 60, 241-64.

Groot, S., J. Mohlmann, J. Garretsen and H. de Groot (2011), "The crisis sensitivity of European countries and regions: stylized facts and spatial heterogeneity", Cambridge Journal of Regions, Economy and Society, 4, 437-56.

ICA, International Cooperative Alliance (2017), Co-operatives and employment.

Istat (2019), Structure and performance of Italian cooperatives: year 2015, in Italian.

Lagravinese, R. (2015), "Regional Resilience and Rising Gaps North-South: The Case of Italy", Cambridge Journal of Regions, Economy and Society, 8, 331-42. 
Lampel, J., A. Bhalla and P. Jha (2014), "Does governance confer organisational resilience? Evidence from UK employee owned business", European Management Journal, 32, 66-72.

Martin, R. (2012), "Regional economic resilience, hysteresis and recessionary shocks", Journal of Economic Geography, 12, 1-32.

Martin, R. and P. Sunley (2015), "On the notion of regional economic resilience: conceptualisation and explanation”, Journal of Economic Geography, 15, 395-437.

Martin, R., P. Sunley, B. Gardiner and P. Tyler (2016), "How Regions React to Recessions: Resilience and the Role of Economic Structure", Regional Studies, 50, 561-85.

Martini, B. (2020), "Resilience, Resistance and Recoverability, Regional Economic Structure and Human Capital in Italy: Are they Related?", Applied Econometrics and International Development, 20-1, 47-62.

Mazzola, F., I. Lo Cascio, R. Epifanio and G. Giacomo (2018), "Territorial capital and growth over the Great Recession: a local analysis for Italy", Annals of Regional Science, 60, 411-41.

Menzani, T. and V. Zamagni (2009), "Cooperative Networks in the Italian Economy", Enterprise and Society, 11, 98-127.

Modica, M. and A. Reggiani (2015), "Spatial Economic Resilience: Overview and Perspectives", Networks Spatial Economics, 15, 211-33.

Navarra, C. (2016), "Employment stabilization inside firms: an empirical investigation of worker cooperatives", Annals of Public and Cooperative Economics, 87, 563-85.

OECD (2021), "The spatial dimension of productivity in Italian cooperatives”, LEED, $2021 / 2$.

Perotin, V. (2012), "The performance of workers cooperatives", in Battilani P. and H. Schroter (eds.), The cooperative business movement, 1950 to the present, Cambridge, Cambridge University Press, 195-221.

Sensier, M., G. Bristow and A. Healy (2016), "Measuring Regional Economic Resilience across Europe: Operationalizing a complex concept", Spatial Economic Analysis, 11, 128-51. 
Veneri, P. and F. Murtin (2016), "Where is Inclusive Growth Happening? Mapping Multi-dimensional Living Standards in OECD Regions”, OECD WP 2016/1.

Ward, B. (1958), "The firm in Ilyria: market syndicalism", American Economic Review, 48, 566-89.

Zamagni, S. and V. Zamagni (2011), Cooperative Enterprise, Chelthenaum, Edward Elgar.

Zamagni, V. (2015), "The Cooperative Movement", in Jones, E. and G. Pasquino (Eds.), The Oxford Handbook of Italian Politics, Oxford, Oxford University Press, 55467. 


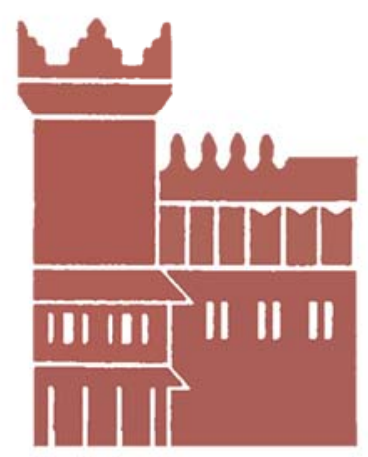

Alma Mater Studiorum - Università di Bologna DEPARTMENT OF ECONOMICS

Strada Maggiore 45

40125 Bologna - Italy

Tel. +39051 2092604

Fax +390512092664

http://www.dse.unibo.it 